\title{
Trayectoria de un profesor productor de saberes: Guillermo Antonio Sherwell, 1878-1914
}

The Professional Career of a Knowledge-Producing Teacher: Guillermo Antonio Sherwell, 1878-1914

\author{
Gerardo Antonio Galindo Peláez \\ Universidad Veracruzana \\ ggalindo@uv.mx
}

\begin{abstract}
Resumen
En las siguientes líneas exploro y analizo la trayectoria de Guillermo Sherwell, un profesor veracruzano que vivió en la confluencia de los siglos XIX y XX e incursionó en los ámbitos del magisterio y la diplomacia. En su fructífero devenir publicó diversas obras destinadas a ser libros de texto en los planteles de educación primaria en México, que se sumaron a la oferta existente de este tipo de libros escolares dentro del sistema educativo del país. Una de las premisas desde las que se aborda a este personaje es el análisis de la obra publicada por docentes, lo que considero una expresión sintética de su formación teórica y de su experiencia de vida en las aulas, saberes construidos y transmitidos en la cotidianidad escolar. Como parte del grupo de intelectuales y profesores que trabajaron alrededor de Enrique C. Rébsamen, Sherwell trasmitió las ideas pedagógicas que en esa época se consideraban, a nivel internacional, las más avanzadas y las plasmó en sus libros de texto -en este caso los de historia- destinados a los alumnos de educación primaria.
\end{abstract}

Palabras clave: educación normal, libros de texto, educación primaria, historia de México.

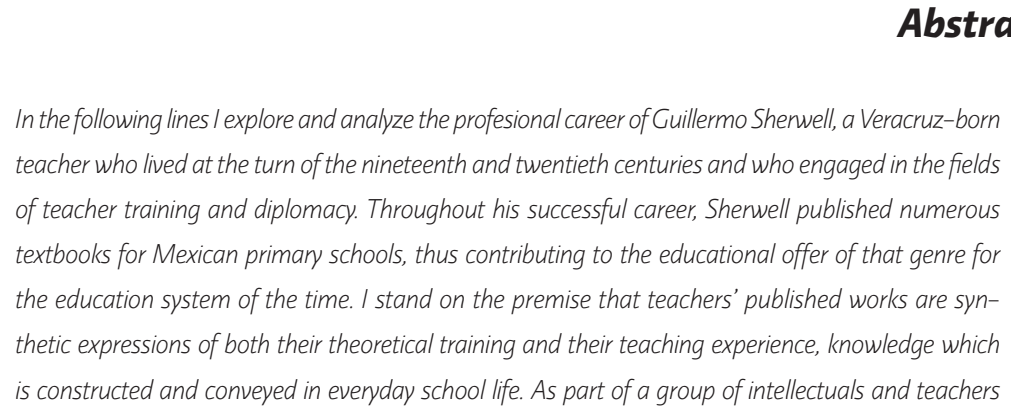


who worked around Enrique C. Rebsamen, Sherwell conveyed in his textbooks what was considered the most internationally-advanced pedagogical ideas of the time. This is evident especially in his history textbooks, analyzed here.

Keywords: teacher training, textbooks, primary education, history of Mexico.

\section{Introducción}

La producción de libros de texto gratuito para el uso de las escuelas de educación básica en nuestro país es un fenómeno consustancial a la segunda mitad del siglo xx que surgió a la par de la necesidad que tuvieron los sistemas educativos en Occidente para adaptarse a la pléyade de cambios que con inusitada rapidez propiciaron diversas transformaciones de la sociedad en su conjunto en todos los ámbitos (Choppin, 2000: p. 25). Sin embargo, el libro escolar en México antecede al libro de texto gratuito con una larga trayectoria que hunde sus raíces en el siglo XIX. En los últimos años esto ha recibido atención por parte de los historiadores, quienes han incursionado en una gran variedad de temas tales como la infancia lectora, las lecturas, sus lectores y las disciplinas escolares en ellos contenidas (Galván y Martínez, 2010: 10).

Los libros de texto ofrecen múltiples aspectos susceptibles de ser abordados, tales como sus autores, las redes de saber implícitas en su construcción, la evolución de los saberes plasmados en sus páginas o la recepción por parte del público lector (Galván, Martínez y López, 2016: 29). En las siguientes páginas me abocaré a desentrañar algunos aspectos de la biografía de Guillermo Antonio Sherwell González y su singularidad como profesor y productor de saberes, específicamente del libro de texto sobre historia nacional que escribió a principios del siglo xx y que por muchos años fue de uso corriente en la educación primaria en México. Para ello, tomo en cuenta lo señalado por Alain Choppin en el sentido de que los manuales escolares no son sólo objetos del ámbito pedagógico, sino vehículos trasmisores de conocimientos y técnicas que una sociedad decide comunicar a las nuevas generaciones (Choppin, 2000: 108-109).

La vida del profesor Guillermo Antonio Sherwell González presenta diversas facetas. ${ }^{1} \mathrm{Al}$ igual que otros personajes de su época conjugó pasiones varias que lo hicieron incursionar

\footnotetext{
${ }^{1}$ En este trabajo me ocupo de la vida de Sherwell en México hasta 1914. Tras su egreso de la Normal de Veracruz, en 1901, Sherwell fue profesor de ese mismo plantel normalista y del Colegio Preparatorio de Xalapa y autor de libros de texto. Posteriormente radicó en la Ciudad de México, donde ocupó diversos cargos en el ramo educativo tales como Director General de Enseñanza Primaria y Jefe de la Sección de Enseñanza Primaria y Normal del Ministerio de Instrucción Pública, éste último en el gobierno de Victoriano Huerta (Olivo, 1998: 194). A la caída de Huerta en 1914, su
} 
en diferentes esferas profesionales. Ciertamente, la escasez de fuentes directas hace difícil su seguimiento biográfico, sobre todo por lo que se refiere a las etapas posteriores a su egreso de la Normal de Xalapa — su actividad laboral, su desempeño como funcionario educativo en la Ciudad de México y su vida después de abandonar el país hacia 1914, cuando se radica en los Estados Unidos de Norteamérica e ingresa a la Universidad de Georgetown como catedrático - y lo relativo a su posterior trayectoria como diplomático hasta su prematura muerte en 1926. No obstante, presento aquí algunos avances y hallazgos logrados en el curso de mis indagaciones. Para ello he utilizado las ideas que en torno a la biografía ha trabajado Françoise Dossé, quien señala que este género puede ser una "manera privilegiada de empezar a restituir una época con sus sueños y sus angustias" y en la que subyace el deseo de "narrar, de comprender" (Dossé, 2007: 15).

El artículo está organizado en tres apartados: Contexto, orígenes y formación, el pensamiento educativo de Sherwell a través de sus disertaciones y Sherwell como productor de saberes.

\section{Contexto, orígenes y formación}

Sherwell nació en la población de Paraje Nuevo, congregación de Amatlán, en el entonces Cantón de Córdoba en el centro del Estado de Veracruz, un 5 de junio de 1878. Tanto el lugar de nacimiento como su época nos muestran algunas de las claves que explican su trayectoria de vida. Fue hijo del coronel William Sherwell, originario de Williamsburg, Virginia, en los Estados Unidos y de Beatriz Catalina González Clavijo, mexicana con antecedentes nobles en España. (Olivo, 1998: 13).

La población de Paraje Nuevo dio también su nombre a la estación de ferrocarril que formaba parte de la ruta ferroviaria del Ferrocarril Mexicano, la primera vía de locomoción que existió en el país y una de las dos que cubría la ruta entre el Golfo de México, entre la costa atlántica y la capital de la república ubicada en el altiplano central. El coronel Sherwell había emigrado a México a principios de la década 1870, empleándose, en diversas entidades de la república, como ingeniero de Ferrocarriles (Pasquel, 1983: 391).

La región cordobesa era, a inicios de la década de 1880, reflejo de los múltiples cambios que el gobierno de Porfirio Díaz impulsaba por todo el país y que tenían como algunos de

salida del país se hizo necesaria ante el avance del constitucionalismo que persiguió a los colaboradores en el gobierno del dictador. Se radicó en Estados Unidos de Norteamérica, donde desarrolló una gran actividad como traductor, profesor en la Universidad de Georgewton y como embajador cultural de ese país en Sudamérica. Escribió las biografías de Simón Bolívar y Antonio de José Sucre. Falleció en 1926 en Washington, D.C. (Zilli, 1966: 253; Olivo, 1998: 199) 
sus protagonistas al ferrocarril y a la construcción del sistema escolar mexicano. ${ }^{2}$ A quince años de la inauguración del primer transporte ferroviario - Ilamado El mexicano - Ilevada a cabo por el presidente Sebastián Lerdo de Tejeda en enero de 1873, en 1888 la región de Córdoba ve surcar nuevas vías férreas como el llamado Ferrocarril Agrícola de Motzorongo, que luego se extendió hacia el Sotavento y con otras vías regionales. Dicho medio de comunicación permitía extraer numerosos productos agrícolas entre los que destacaba la caña de azúcar, la cual se procesaba en la hacienda-ingenio propiedad del ministro de Fomento del gobierno porfirista, el general Carlos Pacheco (Guadarrama, 2013: 216-213).

Este auge del ferrocarril, que era extensivo a numerosas regiones de México en esa época, explica la presencia en Córdoba del ingeniero Sherwell y de su familia, compuesta por su esposa y sus hijos Luis Napoleón, Ana y María, quienes estudiarían en la Normal xalapeña. Más tarde, la construcción de estos caminos de hierro, llevarían al ingeniero hacia Guatemala, donde comenzaba el auge exportador del café y se requerían, como en México, transportes que sacaran el valioso producto hacia las costas del Pacífico y del Atlántico para colocarlos en los grandes mercados norteamericanos y europeos, en una fase de expansión del capitalismo a nivel mundial. En esos afanes le sorprende la muerte en el poblado de Gualam, en los momentos en que se construía una importante vía interna, dejando a su familia en la orfandad (Pasquel, 1983: 391).

A partir de entonces la vida de Guillermo Antonio sufre un vuelco que lo lleva a diversos lugares. Según Leonardo Pasquel, es enviado a estudiar la escuela primaria a la vecina ciudad de Orizaba, sin que sepamos en qué plantel realizó sus estudios. Finalizados éstos el mismo autor señala que se inscribió en la Escuela de Agricultura de México y posteriormente en la Escuela Normal Presbiteriana de la ciudad de Puebla, aunque tuvo que abandonar ese plantel por "un enamoramiento fulminante (que) lo lleva al matrimonio, casando a los diecisiete años de edad con Luisa Velázquez (Pasquel, 1983: 391).

Al parecer, Sherwell tenía vínculos muy estrechos con los miembros de la Iglesia Metodista de México, quienes se hacían cargo de la Escuela Normal para varones en la capital poblana (Fuentes, 1999). De acuerdo con María Eugenia Fuentes Bazán, el Instituto Metodista había sido fundado en la ciudad de Puebla como un orfanato de modestas proporciones, pero para 1897 la matrícula ascendía a 160 alumnos entre internos y externos que provenían de varias partes de la república e incluso del extranjero.

\footnotetext{
${ }^{2}$ De acuerdo con Priscilla Connolly, la mayor parte de la inversión pública durante el régimen de Porfirio Díaz tuvo como objetivo expandir la red ferrocarrilera. El régimen porfirista heredó 424 kilómetros de vías que en su mayoría correspondían a la ruta del Ferrocarril Mexicano, que conectaba a la Ciudad de México con el puerto de Veracruz por la zona de Córdoba y Orizaba. Hacia finales del régimen de Díaz la red ferrocarrilera comprendía 19,280 kilómetros, enlazando a la mayor parte de las regiones del país (Connolly, 1997: 81). Por su parte, los pasos en pos de la construc-
} 
Los metodistas tenían la encomienda de buscar a "jóvenes aptos y cristianos" que pudieran trasladarse a Puebla con el fin de prepararlos al magisterio o como ministros religiosos. Aunque se cobraban cuotas tanto a los externos como a los internos, existían becas para los de escasas posibilidades económicas. La institución se dividía en Kindergarten, escuela primaria, escuela superior, escuela secundaria, escuela Normal, escuela teológica, departamento de comercio y academia de música; en todos se enseñaba el idioma inglés como segunda lengua. El prestigio del plantel era grande, y en opinión del mismo Enrique C. Rébsamen, expresada cuando ya era Director General de Instrucción Normal de la República en 1903, el metodista era el único plantel que disputaba a la Escuela Normal de Xalapa el encabezar el movimiento educativo en el país (Fuentes, 1999).

Al tener que abandonar la Normal en Puebla, Sherwell se dirige a la escuela Hijos de Hidalgo, situada en la población de Miraflores, en el Distrito de Chalco en el Estado de México. En esa población funcionaba una fábrica textil, entre cuyos obreros hacían proselitismo las primeras misiones protestantes que llegaron a México en la década de los setenta. Jean Pierre Bastián señala la existencia de una "red escolar" cuya fundación fue una prioridad de las sociedades protestantes desde sus inicios en México pues no sólo perseguían convertir a los individuos a los principios de su credo religioso, sino también educar a las masas proporcionándoles conocimientos útiles (Bastián, 1993: 144).

Todo hace suponer que Sherwell puso en práctica y completó los conocimientos adquiridos en la normal Metodista pues, según la nota publicada por el periódico El Monitor Republicano y retomada por Bastián, en la escuela de Miraflores se aplicaban, por parte de los tres maestros a cargo, los principios de la institución poblana:

En las tres secciones (kínder, primaria, primaria superior) se sigue el método simultáneo y el sistema de lecciones orales, estando bien aplicado en toda su extensión el sistema objetivo. La enseñanza de la geometría general está hábilmente mezclada con la historia patria y universal y con la instrucción cívica y moral. Acostumbran hacer los alumnos recitaciones en alta voz que equivalen a la vez a ejercicios de alta lectura y de desarrollo de la memoria (...). En gimnasia de salón, especialmente las niñas tienen ejercicios verdaderamente notables; toda esta gimnasia se hace por medio de la música (Bastián, 1993: 154).

Entre 1897 y 1900 Sherwell ocupó la dirección de la escuela mexiquense, y en el último año solicitó su ingreso a la Escuela Normal de Xalapa. La constancia de sus servicios la firmó John William Butler quién había sido agente de la Sociedad Bíblica Británica y quién había

ción de un sistema escolar propio se enmarcan, también, "en el proyecto modernizador del Estado, el cual asume formalmente el servicio educativo" (Ducoing, 2012: 16). 
obtenido licencia del emperador Maximiliano hacia 1864 para vender biblias, convirtiéndose posteriormente en uno de los impulsores del metodismo en México. ${ }^{3}$

Pero la decisión de ingresar en la Normal veracruzana también estuvo influida por la presencia en esa escuela de su hermana Ana Sherwell, quien cursaba sus estudios en ese plantel y quien, a decir de Pasquel, le proporcionó los contenidos necesarios para que presentara exámenes y en poco tiempo obtuviera el título de profesor de educación primaria elemental y superior. ${ }^{4}$

Una reflexión más allá de ese hecho es la existencia de redes de relaciones ${ }^{5}$ entre los profesores que ejercían su labor intelectual en esa ciudad y cuyas influencias llegaban a otros ámbitos del país. Para ese entonces muchos egresados de Xalapa estaban formando instituciones similares o trasmitiendo las propuestas pedagógicas de Rébsamen y su prestigio era considerable; se constituían, en palabras de Leticia Moreno, en "intelectuales educativos" formando una élite con rasgos bien definidos (Moreno, 2011: 2). En el caso de Sherwell es de notarse la opinión favorable que tenía el pedagogo suizo de la Normal metodista de Puebla, lo que facilitó su ingreso. Además, seguramente las estrechas relaciones que éste tenía con varios planteles fueron definitivas para su eventual nombramiento como director de Educación Normal en el país. Algunas otras actividades realizadas por el mismo Sherwell a su egreso de la Normal xalapeña dan cuenta de las facilidades que, gracias a la pertenencia a esa élite de intelectuales educativos, tuvo para desempeñarse en diversos ámbitos. Entre sus diversos puestos destacan: el de Director de la Escuela Superior para Varones Juan de la Luz Enríquez, en la ciudad de Xalapa, que formaba parte de las Escuelas Cantonales en el Estado; el de profesor de Pedagogía y Metodología en la Enseñanza de la Historia en la misma Escuela Normal de la que había egresado; el de catedrático en el Colegio Preparatorio de Xalapa donde impartió las materias de historia y francés; finalmente, destaca la comisión que el gobernador Teodoro A. Dehesa le otorgó para estudiar la organización de las escuelas secundarias en los Estados Unidos de Norteamérica (Olivo, 1998: 195).

\footnotetext{
${ }^{3}$ Archivo de la Escuela Normal Veracruzana (en adelante AEnV), Año 1900, Sección Secretaría, "Sherwell, Gui\|lermo. Sus exámenes para obtener el título de Profesor de Escuela Primara Elemental y Superior", Expediente No. 24, foja s/n; Bastián, 1993, p. 36. Hay informaciones que muestran el activismo de Butler en la propagación del credo metodista así como en sus órganos de difusión y propaganda (Martínez, 2013: s/p.). (Trujillo, 1997: 317).

${ }^{4}$ Ana Sherwell ingresó a la Normal de Xalapa en enero de 1897 como alumna pensionada por el cantón de Córdoba. En mayo de 1902 recibió el título como Profesora de Instrucción Primaria Superior. Posteriormente laboró en la Escuela Cantonal de Córdoba (García, 2003: 88).

${ }^{5}$ El término "redes" o "redes sociales" lo utilizo para dar a conocer y analizar la estructura de las relaciones entre individuos o agrupaciones en su interacción hacia la sociedad, en el marco de un sistema en el que muestran su funcionalidad (González y Basaldúa, 2007: 1).
} 


\section{El pensamiento educativo a través de las disertaciones}

El plan de Estudios de la Normal de Xalapa de agosto de 1886 estipulaba que los alumnos que deseaban realizar la carrera de Profesor de Instrucción Primaria Elemental debían cursar tres años de estudio y, dos años más, los que aspiraban a obtener el título de Profesor de Instrucción Primaria Superior, haciendo una suma de cinco años y cuarenta y cinco materias en total, pero los planes de estudio fueron variando con el tiempo (García, 2003: 41-43). Es de notarse que, desde su fundación en 1886 y hasta 1905, la Escuela Normal de Xalapa no contó con un reglamento oficial que rigiera las actividades del plantel, por lo que casos como el de la admisión de Sherwell y otros similares se resolvieron de acuerdo con las decisiones del Director, es decir Rébsamen, y la junta académica (Arteaga y Camargo, 2014: 278). ${ }^{6}$

Las materias que presentó en dos días de exámenes, fueron: Antropología Pedagógica I y II; Español I, II y III; Aritmética I, II y III; Inglés III; Caligrafía I y II; Teneduría de Libros I; Ciencias Naturales I y II; Francés I y II; Historia |I y III; Geografía I, II y III; Instrucción Cívica III; Álgebra I I y III; Dibujo; Pedagogía III; Geometría I, II y III; Higiene III; Canto I, II y II y Gimnasia. Una buena parte de la planta docente normalista, incluyendo el propio Rébsamen, fungieron como sus sinodales. La calificación total de todos los exámenes presentados fue de 473 puntos, que rebasó en mucho los 330 requeridos para ser aprobado?

Una vez promovido en estas materias, Sherwell presentó el examen profesional para obtener el grado de Profesor de Primaria Elemental, el cual consistió en una disertación oral sobre algunos de los contenidos que conformaban el currículum normalista y la exposición y desarrollo de una temática. La reglamentación administrativa establecía que, una vez acreditados los exámenes de los contenidos de la currícula, los estudiantes que aspiraban al título de primaria elemental o superior debían dirigir una solicitud al director para realizar el examen con el que culminarían sus estudios. Uno de los requisitos era presentar una disertación sobre algún tema pedagógico seleccionado al azar de una lista elaborada por el personal docente. Al alumno se le notificaba la temática cuatro días antes de realizarse el examen, y un día anterior al mismo debía presentar un escrito alusivo a la misma. El día del examen el estudiante daba lectura al tema que había preparado; posteriormente el jurado

\footnotetext{
${ }^{6}$ Existe la mención de un reglamento de este tipo de exámenes hacia 1894, pero no se localizó en el Archivo de la Escuela Normal. El Reglamento de 1909 es el más antiguo que de manera oficial se menciona y conserva. La forma de realizar los exámenes a Sherwell en 1900 no se diferencia, en lo general de lo que ese reglamento estipula, Véase AENV, Año 1909, Caja 271, Serie Reglamentos, Legajo, 1. El primer reglamento de los exámenes de tipo ordinario y en general los que servían para evaluar todas las materias que cursaban los alumnos fue expedido el 9 de noviembre de 1888 (Zilli, 1961: 41-43)

${ }^{7}$ AENV, Año 1900, Sección Secretaría, "Sherwell, Guillermo. Sus exámenes para obtener el título de Profesor de Escuela Primara Elemental y Superior", Expediente No. 24, foja s/n.
} 
expresaba sus observaciones y o refutaciones, tras lo cual el alumno tenía que hacer la defensa de su trabajo. Luego se hacía una evaluación oral de los conocimientos generales que poseía el sustentante para después pasar al examen práctico o lección de prueba en la que hacía una exposición de una clase a un grupo escolar de la Escuela Práctica Anexa (García, 2003: 50-51).

La temática que Sherwell redactó y expuso se tituló "Cualidades personales que debe reunir el maestro". En este escrito señaló las características esenciales de un buen educador, a saber: cualidades físicas, intelectuales, éticas, estéticas y modales. Afirmó que el maestro ha sido a lo largo del tiempo "el resumen y sintetización del carácter social de una época" pues en el se reflejaban las virtudes o defectos del entorno que le rodeaba.

En cuanto a las cualidades físicas, Sherwell afirmó que un maestro debía poseer las que ayudaran en el desempeño de su labor; si su cerebro era "débil" o si su salud delicada "era imposible que pueda soportar la vida sedentaria que le impone su trabajo" por lo que debería mantener un buen estado de salud. Afirmaba que no consideraba una exageración el que en algunos lugares se prohibiera el magisterio a las personas que adolecieran de una deformidad corporal notable pues, en su concepto, "era fácil comprender cuán difícil sería para un maestro en esas circunstancias hacerse respetar por sus discípulos." ${ }^{8}$ En lo que respecta a las características intelectuales que cualquier profesor debería tener, consideraba que, sin pretender que el maestro fuera un sabio, tenía que poseer un conjunto de conocimientos mayores que los de sus alumnos, pues a su parecer nada era "más ridículo" que un maestro que no pudiera contestar a las preguntas de sus discípulos. Debía el profesor poseer también un juicio claro para discernir en qué casos son aplicables ciertos principios y cuando no. También consideraba que un buen profesor debía tener facilidad para la expresión de sus pensamientos. ${ }^{9}$

Refiriéndose a las cualidades éticas y estéticas mencionaba que el maestro debería ser "un hombre de voluntad firme". Citando a Spencer, ${ }^{10}$ concluye que, sin ser un tirano, el maestro debería cumplir sus propósitos, pues un mentor que amenaza y no cumple se convierte

\footnotetext{
${ }^{8}$ Estas ideas están en consonancia con la difusión de la doctrina positivista en México a través del grupo de Gabino Barreda y sus discípulos después del triunfo de la república en 1867. El positivismo preconizaba el orden y el progreso y, de acuerdo con su fundador Augusto Comte, era una doctrina dirigida a trasformar a la sociedad para dirigirla hacia la felicidad permanente. Los instrumentos para dicho cambio eran la aplicación de una "ciencia social" y la aplicación de los principios científicos para el análisis y la solución de las distintas problemáticas. Una de las leyes biológicas que debían aplicarse para la solución de esos problemas era la supervivencia del más apto. Manuel Ramos, uno de los seguidores de Barreda, señaló que en la sociedad no debían sobrevivir sino los más fuertes física e intelectualmente, y que el Estado no tendría otra misión que facilitar estas aptitudes y no atrofiarlas concediendo facilidades. El gobierno no tendría que preocuparse de que perecieran los débiles, ya que de ello se desprendería el "bien social" (Zea, 1968: 175).

${ }^{9}$ AENV, Año 1900, Sección Secretaría, "Sherwell, Guillermo. Sus exámenes para obtener el título de Profesor de Escuela Primara Elemental y Superior", Expediente No. 24, foja s/n.

${ }^{10}$ Herbert Spencer, naturalista, filósofo, sociólogo, psicólogo y antropólogo inglés.
} 
en un "juguete, el hazme reír de sus alumnos". Ello, en su opinión, no se contradecía con el "amor profundo y sincero por sus alumnos e incluso por los que más disgustos le hayan dado pues afirmaba que el maestro que llegara a odiar a un niño "es indigno de desempeñar su noble profesión". 1 .

Sherwell finaliza su disertación refiriéndose a las cualidades éticas y estéticas de un "buen pedagogo". Afirma que el aseo personal es importante tanto como el cuidado en el vestir sin llegar a un lujo ostentoso; que el ser afable con todos es una cualidad que facilitaría el hacerse querer por los discípulos; que la puntualidad debía ser observada siempre y en todo lugar, pues, en su opinión, muchos maestros fijan en las paredes de sus escuelas lemas alusivos cuando también deberían "fijar estos lemas en su casa y se los aplicaran a la propia personalidad"; de igual importancia era que el mentor observara una conducta sin "tacha" para que nadie lo pudiera acusar de "ebrio, jugador y vicioso" pues su respetabilidad estaba basada en el ejemplo a sus discípulos y a la sociedad, ejerciendo una positiva influencia en su entorno. Ello estaba en consonancia con la atención que el alcoholismo, entre otros vicios, provocaron en la clase dirigente durante el porfiriato, al grado de considerárseles una "calamidad nacional" (González, 1985: 72-73).

Como epílogo, Sherwell comenta que el profesor deber hacer un balance de sus cualidades, estudiar bien sus "caracteres" y alejarse de la idea de que es perfecto, pues "la obra de perfección del hombre nunca se acaba; con esta convicción trabajará siempre y hará el mayor bien a sus semejantes."12

Una vez presentado y aprobado este examen, Guillermo Antonio Sherwell obtuvo su título de Profesor de Instrucción Primaria Elemental en agosto de ese mismo año de 1900.13 En julio del siguiente año solicitó presentar los exámenes para obtener el grado de Profesor

${ }^{11}$ AENV, Año 1900, Sección Secretaría, "Sherwell, Guillermo. Sus exámenes para obtener el título de Profesor de Escuela Primara Elemental y Superior", Expediente No. 24, foja s/n.

12 lbid.

${ }^{13}$ AENV, Año, 1900, Sección Secretaría, Expediente No. 24, 31 de agosto, foja s/n. Desde la promulgación de la Ley Orgánica de Instrucción Pública en agosto de 1873 por parte del gobernador de Veracruz, Francisco Landero y Cos, la educación primaria se subdividía en "elemental" y "superior". La primera comprendía la enseñanza de la lectura, caligrafía, aritmética elemental y moral en los planteles situados en áreas rurales. En las que se ubicaban en áreas urbanas, además de tratar con "mayor extensión" las anteriores materias, se agregaban: elementos de geografía universal, general de México y particular del estado; elementos de historia de México y elementos de gramática castellana. En ambos casos la orientación de esos aprendizajes debería estar en función del contexto rural o urbano: para el primero los conocimientos deberían aplicarse a las "necesidades de la vida agrícola"; para el segundo, a lo requerido por la industria y comercio. La primaria "superior" se enfocaría en el perfeccionamiento de lo aprendido en la elemental, agregando nociones generales de física y de historia natural, principios de geometría, elementos de teneduría de libros e idioma francés y dibujo natural y lineal. En las escuelas superiores para niñas se agregarían los cursos de higiene doméstica y primeros socorros médicos, ciencias físico-naturales en sus aplicaciones a la vida doméstica, conocimiento teórico práctico de las máquinas y aparatos de coser, lavar, etc., economía doméstica, idioma francés o italiano, o ambos a la vez y música vocal e instrumental. (Blázquez y Corzo, 1997: 624-625). 
de Primaria Superior, correspondiente al Iv y v cursos que se establecían en la Normal para ese fin. Las materias en las que fue examinado eran: disertación pedagógica, gramática general, literatura moral, filosofía de la historia, lógica, economía política, geografía astronómica, ciencias naturales, lección de prueba, inglés, algebra y trigonometría, en las cuales también resultó aprobado. ${ }^{14}$

De manera similar a los exámenes para obtener el título de profesor de educación primaria elemental, el sustentante tuvo que realizar una disertación oral y escrita como examen profesional para acceder al grado de mentor de la primara superior. El documento llevó el título "¿Deben establecerse jardines escolares en México?" y en él tuvo oportunidad de dar a conocer sus lecturas y experiencias en el campo docente. Cabe señalar que tanto la disertación sobre las cualidades del profesor como la de los jardines fueron publicadas en la revista México Intelectual, uno de los órganos de difusión pedagógica más importantes de esa época, dirigido por Rébsamen.15

Cabe señalar que el grupo formado por Rébsamen y sus colaboradores en la Escuela Normal de Xalapa estaba al tanto de las innovaciones pedagógicas y científicas de esa época, pues sus integrantes mantenían comunicación con sociedades científicas, instituciones educativas, autoridades gubernamentales, periódicos, revistas y boletines de ciencia, así como las novedades bibliográficas nacionales e internacionales en una gran variedad de temáticas. En el caso de Sherwell, el tema de los jardines escolares era de una gran actualidad en Alemania y Austria a finales del siglo XIX: en 1869 el pedagogo oriundo de Leipzig, Daniel Gottlob Moritz Schreber, había creado los Schrebergarten o jardines urbanos que, en el contexto de la industrialización que se vivía en esos tiempos habían sido pensados para satisfacer la necesidad de un mayor contacto de los niños con la naturaleza y el aire puro, así como brindar áreas para el juego y la recreación dentro de las áreas urbanas. Además, Schreber proyectó la posibilidad de que en los jardines ubicados en medio de las ciudades los niños recibieran la enseñanza de la agricultura por medio de la siembra y cuidado de plantas acercándose de algún modo al medio rural. ${ }^{16}$

\footnotetext{
${ }^{14}$ AENV, Año, 1900, Sección Secretaría, Expediente No. 24, 22, 25 y 26 de agosto, foja s/n.

${ }^{15}$ AENV, Año 1900, Sección Secretaría, "Sherwell, Guillermo. Sus exámenes para obtener el título de Profesor de Escuela Primara Elemental y Superior", Expediente No. 24, foja s/n. México Intelectual fue una de las revistas pedagógicas más importantes de México entre 1889 y 1904. Conjuntó una serie de esfuerzos de varios profesores de la Normal xalapeña, alumnos y otros colaboradores allende Xalapa. En ella se escribieron numerosos artículos pedagógicos, noticias educativas del país y del extranjero, hubo una amplia correspondencia con otras revistas y periódicos nacionales e internacionales y se convirtió en un vehículo de comunicación de las ideas más sobresalientes en el ámbito educativo e intelectual de esa época, así como de los avances escolares y académicos del plantel veracruzano (Moreno, 2016: 304).

${ }^{16}$ http://alemaniaentrebastidores.blogspot.com/2014/05/schrebergarten-kleingarten.htlm, consultado el 17 de enero de 2019. Aunque la influencia francesa en las politicas educativas del porfiriato llegó a convertirse en un modelo
} 
Tomando en consideración las ideas anteriores, el profesor cordobés aseveró en su disertación que el establecimiento de jardines escolares sería una de las manifestaciones más "importantes" del trabajo manual y que su puesta en marcha se había verificado en varios países de Europa, principalmente en Austria. Sentenciaba que "es seguro de que no pasará mucho tiempo sin que sea reconocida su capital importancia y sea un hecho su establecimiento en todo el mundo".

Sherwell inició su exposición con el apartado "Ventajas del jardín escolar", el cual subdividió en cuanto al "fin material", al "fin formal" y al "fin ideal" de la enseñanza. Del primero señalaba que con un huerto o jardín escolar los alumnos adquirían conocimientos para enriquecer con ellos su inteligencia, pues el acercarse a los abonos, tipos de suelos, la clasificación vegetal y el conocimiento de las plantas útiles y nocivas se posibilitaba la unión de la práctica con la teoría. En su opinión, la teoría era "destructora de la inteligencia" cuando se empleaba sola, como "por desgracia pasa en gran parte del país".

El aprendizaje sería más firme, en opinión del expositor, si en vez de enseñar teóricamente las partes y cualidades de una planta, se instruía a los alumnos para cultivarla; de ese modo los conocimientos adquiridos en el aula quedarían grabados "muy bien" en la mente de los alumnos, que además lograrían dicho conocimiento "por sí mismos".

El fin formal de la enseñanza lo definió como "la educación de las facultades intelectuales" para que los jóvenes, al egreso de la escuela primaria, "tengan bien formado su criterio y estén aptos para la vida". En su concepto, la inclusión de las prácticas de agricultura mediante el jardín escolar desarrollaría en los educandos las seis partes en que se dividen dichas facultades, a saber: la percepción, la memoria, la imaginación, el juicio, el raciocinio y la abstracción. En la exposición hace una abigarrada descripción de cada una de ellas, citando a autores como Compayré, Bain o Comenio, para afirmar que nada hay en la inteligencia que no haya estado antes en los sentidos. ${ }^{17}$ De tal manera que el niño que se acostumbraba a limpiar de parásitos las plantas, o a calcular su fuerza vital por el color de las hojas o la rigidez del tallo, sería como un "pintor que ha educado su vista". La memoria se ejercitaría con la experiencia repetida por el niño al interactuar con las plantas.

Sherwell desarrolla ampliamente las bondades de su jardín escolar para el desarrollo de las otras cualidades como la imaginación, el juicio, el raciocinio y la abstracción. Al finalizar asegura, con poca modestia, que su idea es mejor que los "Dones de Froebel juntos" pues la

\footnotetext{
para la realidad escolar mexicana (Ducoing, 2012: 73-74), también existió, en el caso de Rébsamen, su revista y el círculo de profesores que le rodeaba, una marcada influencia de la pedagogía y la ciencia alemana. La correpondencia y un numero considerable de artículos publicados en la revista México Intelectual así lo muestran.

${ }^{17}$ Gabriel Compayré fue un escritor y pedagogo francés que vivió entre 1843 y 1913. Alexander Bain (1818-1903) fue un filósofo, psicólogo y educador escocés.
} 
pelota, la esfera o el cubo no presentan la variedad ni tienen los niños el atractivo que tiene un jardín. ${ }^{18}$

Con respecto al fin ideal, que es concebido por el autor como la "educación del ser moral y el perfeccionamiento de las facultades éticas y estéticas" y que tienen como objeto formar el carácter, fortalecer la voluntad", nada era mejor que predicar con el ejemplo o la acción. En esta parte, Sherwell desarrolló una crítica a la forma de ser de los mexicanos, señalando que somos de una "exquisita sensibilidad" ya que nos conmovemos por cualquier cosa y tenemos "innata" la gran facultad cristiana de "llorar con los que lloran":

Sabemos, excediendo á no sé que santo, dar nuestra capa á áquel que tiene frío. Los resultados son atroces: la prodigalidad seguida de la miseria; la subordinación absoluta de nuestra razón a nuestras pasiones; el vicio que corroe y mata a las sociedades; la miseria y la mendicidad que pasean su harapos sobre la tierra que da en abundancia lo que se le pide ique gran estudio sociológico se puede hacer tomando como base la sensibilidad del carácter mexicano! y yo no lo haré, al menos por ahora, quien sabe si después tenga el valor de aspirar la fetidez de esos antros...y me temo que mucho y muy desagradable tendrá que decirse de la escuela primaria mexicana. $^{19}$

En este punto Sherwell hace una digresión para mostrar cómo tanto en la escuela como en la familia se inculcaba a los niños un falso sentido de lo que es la abnegación y la caridad, volviéndolos muy sensibles, provocando que la sociedad se llenara de una "inmensa caterva de mendigos" y de holgazanes mantenidos por ella. Especificó además que la caridad pública que se encargaba de los viejos en los asilos era una virtud, pero la caridad privada "sostiene vicios y fomenta la prostitución" lo que se convertía en un delito de "lesa sociedad". En su visión, los países "grandes" eran los "clásicos del egoísmo" pues las palabras "tuyo" y "mío" tenían verdadero valor, y en ellos todos los habitantes se sometían al imperativo de la ley de la lucha por la vida que dictaba "el que no trabaja, no come, sin excepción". Derivado de lo anterior afirmó que de la escuela mexicana salían muchos, los menos como "protectores" y

\footnotetext{
${ }^{18}$ Federico Froebel (1782-1852) fue un pedagogo alemán nacido en Oberweissbach, Turingia. Estudió en la Universidad de Jena y trabajó en las Universidades de Gotinga y Berlín. Recibió influencia del pedagogo suizo Johann Heinrich Pestalozzi. Concebía que la naturaleza estaba dotada de una estructura interna por lo que pensaba que todos los planes y programas de estudio deberían tener unidad y continuidad relacionando los contenidos entre sí. Los "dones", como la esfera, el cilindro y otras figuras geométricas, eran objetos con significado matemático, por lo que al ser introducidos sistemáticamente para que el niño jugara libremente con ellos, este asimilaría paulatinamente la estructura y unidad del mundo (Heiland, 1999).

${ }^{19}$ AENV, Año 1900, Sección Secretaría, "Sherwell, Guillermo. Sus exámenes para obtener el título de Profesor de Escuela Primara Elemental y Superior", Expediente No. 24, foja s/n.
} 
los más como "protejidos" que escogían ese papel "que implica trabajo para adquirir dinero" convirtiéndose en holgazanes. ${ }^{20}$

Completó esas ideas diciendo que había aversión hacia el trabajo en el campo, que incluso el campesino quería que sus hijos se volvieran abogados o médicos siendo que el país necesitaba de campesinos que hicieran producir la tierra. Propuso que, en vez de estar creando colonias con gente extranjera, debería de haber "colonias de mexicanos" recogiendo "a los vagos y arrojándolos al campo" para que produjeran sus propios alimentos y supieran el valor de su trabajo. Estas ideas estaban en consonancia con la visión que los liberales y o positivistas tenían de la realidad nacional. ${ }^{21}$

Por lo anterior ponderó el trabajo del jardín escolar, que infundía en los niños la perseverancia, el amor por el trabajo, la idea de propiedad, un carácter firme e iniciaba el camino para adquirir trabajos "competentes". Finalizó su exposición argumentando en contra de los supuestos "inconvenientes" que pudiera presentar el establecimiento de esos jardines en las escuelas mexicanas.

Es necesario señalar que en el caso de las "disertaciones" que equivaldrían a lo que hoy se conoce como exámenes profesionales, la temática tratada tuvo, como ya hemos señalado, una expresión en la revista México Intelectual, pero no fue modificada o ampliada en dicha publicación y al parecer Sherwell no la abordó posteriormente. Como era de esperarse, Sherwell logró la aprobación del jurado y obtuvo su título de Profesor de Instrucción Primaria Superior, con lo que da por terminada, al menos en México, su formación como docente y retoma sus actividades laborales en la misma Normal veracruzana y en el Colegio Preparatorio de Xalapa.

\section{Productor de saberes}

Una de las facetas que dio a conocer a Sherwell en el ámbito educativo nacional, una vez que egresó de la Normal xalapeña, fue la creación de libros de texto. Diversas obras para uso de los alumnos de primaria salieron de su pluma; la más conocida fue la serie de "Historia Patria" dividida en tres libros que escribió para los alumnos de educación primaria. En la

${ }^{20}$ Estas ideas retoman el pensamiento que los positivistas porfirianos tenían de la sociedad, considerándola un campo de batalla en donde sólo sobreviven los más aptos, o sea, los miembros de la burguesía mexicana. Según esta visión, la tarea del Estado era la de proteger los intereses de ésta y evitar hacerlo con los menos favorecidos. A la burguesía le corresponden todos los derechos pues los "inadaptados" no deben recibir ni siquiera la compasión - la limosna públicas. El Estado tendría que vigilar que se cumpliera lo anterior para garantizar el respeto por las conquistas de la burguesía mexicana, fruto del esfuerzo personal y respaldar a los más aptos.

${ }^{21}$ La realidad mexicana se observaba desde esa perspectiva "científica" y por lo tanto se trataban de aplicar "leyes" generales como la de "sobrevivencia del más apto" o se ahondaba en la discusión sobre las causas del atraso de un sector de la población (Hale, 1991). 
Junta Académica de la Escuela Normal de Xalapa celebrada el 8 de junio de 1904 se aprobó la obra de este egresado de la misma con un dictamen favorable para su publicación. Hay que señalar que desde 1887 la Escuela Normal de la Ciudad de México era la institución designada para emitir dictámenes sobre libros de texto que recibía la Junta Directiva de Instrucción Pública para su visto bueno. Al aumentar la producción editorial y por ende la demanda de revisiones, a finales del siglo XIX se acordó que esta tarea se delegara en las academias de profesores en cada estado de la república lo que, aunado al prestigio de la escuela normal dirigida por Rébsamen, hizo que sus dictámenes fueran muy valorados en el medio educativo (Martínez, 2014: 291-316). Para mostrar aún más la benevolencia con que fue recibida esta obra, el gobierno del estado, a cargo del gobernador Teodoro A. Dehesa, adquirió 5500 ejemplares para distribuirlos en las escuelas primarias de Veracruz (Zilli, 1961: 56).

Estos textos salieron a la luz pública por primera vez en 1904 y se reimprimieron en más de doce ocasiones. ${ }^{22}$ Cómo veremos en las siguientes líneas, el autor reprodujo el esquema de la historiografía dominante en ese periodo en lo relativo a la enseñanza de la historia para las escuelas primarias del país; es decir, buscó, en lo general, exaltar el patriotismo, enfatizar la idea de patria y promover valores como la solidaridad, la unión y la cohesión entre los mexicanos (Martínez, 2013: 170-171). ${ }^{23}$

Para situar esta obra en su justa dimensión, parto de la consideración del libro como el "resultado de un sistema complejo de relaciones" (Mendiola y Zermeño, 1994: 54); por lo tanto, su elaboración tiene que ver con el contexto de su elaboración, sus propósitos y las expectativas que se sitúan alrededor de su recepción. De esa manera es posible decir que el texto analizado tiene como origen las ideas vertidas por Enrique C. Rébsamen, pues Sherwell siguió al pie de la letra el planteamiento que el educador suizo desarrolló en la Guía Metodológica para la enseñanza de la historia en las escuelas primarias elementales y superiores de la República Mexicana, adaptando algunos elementos pero en lo general siguiendo las enseñanzas de su maestro. ${ }^{24}$ Así, Sherwell recupera la noción de Rébsamen de que la historia debe

22 La edición que utilizo para este análisis es la correspondiente al segundo curso, publicada en 1957 por Editorial Patria.

${ }^{23}$ Algunas de las obras que circulaban en ese tiempo eran Lecciones de Historia patria escritas para alumnos del Colegio Militar, de Guillermo Prieto, La Patria Mexicana, Elementos de Historia nacional y Catecismo Elemental de la Historia de México, desde su fundación hasta mediados del siglo XIX, de Justo Sierra, entre otros (Galván, 2010: 111-140). La publicación de la obra de Rébsamen referente a la enseñanza de la historia dio pauta a una fuerte polémica entre Guillermo Prieto y el director de la Normal de Xalapa, misma que trascendió a la opinión pública entre enero y febrero de 1901. El principal motivo de la diferencia era que Rébsamen señalaba la necesidad de separar el estudio de la historia del civismo y la moral, mientras que para Prieto eran inseparables, pues su fin consistía en sensibilizar a los niños respecto a lo bueno y lo malo (Ortega y Medina, 2001: 331-354; Moreno, 2016: 305). Un listado más amplio de libros de texto de historia de México puede verse en Vázquez (2000: 111-141).

24 Un trabajo que refleja tanto la biografía de Rébsamen como su labor en la educación nacional y sus contribuciones es el de Irma Leticia Moreno Gutiérrez (2016: 287-313). 
servir para el perfeccionamiento de las facultades intelectuales del niño, desarrollando la memoria a través de ejercicios para la "retención de los hechos", e insistiendo en el valor de la historia para la educación moral y cívica. Es necesario hacer notar que este libro se publicó justo en el año de la muerte de Enrique C. Rébsamen, circunstancia que llevó a muchos de sus discípulos a transmitir la obra de su maestro.

La historia, de este modo, serviría como portadora de ejemplos que mostraban la generosidad, la abnegación y demás virtudes morales y cívicas, así como sus opuestos: el egoísmo, la tiranía y la abyección (Rébsamen, 1904: 12-13). Los manuales de Sherwell, Rébsamen, Justo Sierra y otros que se publicaron en esa época tuvieron como marco general las discusiones y disposiciones emanadas de los Congresos Nacionales de Instrucción Pública de 1889-1890 y 1890-1891, en donde Rébsamen tuvo un papel protagónico respecto a la elaboración de los contenidos de la enseñanza de la historia. En dichos congresos se trabajó por la uniformidad de la enseñanza en todo el país, cumpliendo con el anhelo liberal de formar ciudadanos acordes con la ideología del nuevo Estado; para ello se requería que todos fueran formados en los mismos ideales y que los contenidos de la enseñanza fueran moldeados a la luz de las ideas liberales y positivistas imperantes en ese entonces (Vázquez, 2000: 110-112).

Pero no sólo eran la memoria y los valores lo que la enseñanza de la historia debía atender, según el pensamiento rebsamiano, sino que también debía fomentarse el desarrollo de la imaginación, pues el alumno debía recrear en su mente los grandes personajes históricos y los lugares donde se verificaron los sucesos. En este sentido, Sherwell recurrió en su texto al uso abundante de pasajes pletóricos de imágenes que tenían la finalidad de estimular la mente infantil. Al mencionar la salida del ejército de Hidalgo al encuentro de las tropas realistas en Guadalajara, describió la escena de la siguiente manera:

Salió, pues, la chusma insurgente con sus pocos fusiles viejos, sus hondas, sus garrotes, sus machetes mohosos, sus arcos y sus flechas. Tocaban los tambores y las chirimías, y unas ramas y unos trapos servían de banderas...! (Sherwell, 1957: 22).

Un tercer aspecto a desarrollar en la enseñanza de la historia, siguiendo el pensamiento de Rébsamen, era el juicio y el raciocinio para "descubrir las relaciones de causalidad de los sucesos entre sí”. Así, en la lección referente a la Independencia nacional Sherwell hace relaciones entre los acontecimientos y sus consecuencias:

Pudiera creerse que después de consumada la Independencia nacional el país entró en una era de dicha y de prosperidad. Más no fue así. La obra de la dominación española consistió en formar la unidad de la nación en vez de la multiplicidad de pueblos y tribus que antes había. Después vino la obra de hacer la independencia de esa nación ya unificada (Sherwell, 1957: 60). 
Para el autor, la historia es la narración de los sucesos pasados en los que ha intervenido el hombre, por lo tanto la de México abarcaría esa narración desde los tiempos más remotos hasta la actualidad, dividida en tres etapas: "la época antigua, la época colonial y la época moderna o de México independiente". Por su parte, la historia universal o general se ocuparía de los "acontecimientos ocurridos en los principales países del mundo". La visión de Sherwell sobre la historia es que es "la maestra de los hombres" pues enseña con ejemplos lo bueno y lo malo, "lo que se debe de hacer y lo que se debe evitar".

En el primer libro Sherwell aborda el estudio del devenir de México remontándose a la época precortesiana y analiza el peregrinaje de distintas tribus nómadas o sedentarias que fueron el cimiento de "naciones distintas"; entre ellas destacaron la tolteca, que alcanzó una "gran cultura y rápida decadencia", y la de los aztecas o mexicanos, que sobresalieron por la rápida transformación que experimentaron al convertirse rápidamente en una tribu civilizada y por la resistencia que opusieron a los conquistadores "extranjeros".

La etapa de la conquista es el otro gran tema de ese primer libro. En ella resaltó tanto las hazañas de Hernán Cortés como los esfuerzos de los aztecas -a los que califica como "gloriosos"- por defender su territorio. Finalmente hace un recorrido por lo más sobresaliente de la época colonial y pone énfasis en el hecho de que indios y mestizos fueron mezclándose hasta formar la raza de los mestizos que en su opinión es la preponderante.

El segundo libro está dividido en cincuenta y seis lecciones que abarcan desde el siglo XIX al XX, dedicándole el último capítulo a lo que el autor entiende como "definición" y "división" de la Historia.

La primera lección la denomina "recordación" y le sirve para enlazar los contenidos del primer curso con el segundo, resumiendo los temas abordados. En la segunda lección retoma la situación de México antes de la independencia; lo que no había señalado en ese primer libro respecto a su concepción de la época colonial lo hace ahora, calificando la situación de los habitantes de la Nueva España como "insoportable". Pues, aunque admite que una parte de los virreyes fueron "bondadosos, enérgicos y honrados", señala que la mayor parte de los españoles que se desempeñaban en cargos menores del gobierno colonial eran "hidalgos pobres o individuos necesitados que procuraban enriquecerse a toda costa, y para lograrlo explotaban despiadadamente al pueblo" (Sherwell, 1957: 9). Para decirlo más claro, el autor señala, al finalizar el repaso de los contenidos del libro anterior, que todo ello se había visto en ese volumen previo y que había "suspendido" ese estudio cuando "llegamos a los principios del siglo diez y nueve, por el año de 1810. Como de entonces acá han pasado muchos años y han sucedido acontecimientos aún más interesantes que los ya vistos, vamos a continuar nuestra narración en este librito". La idea era explicar cómo el país en un siglo pasó "poco a poco" desde la época colonial hasta un estado que, según sus palabras, era "próspero, floreciente, rico en hermosas realidades y en brillantes promesas". 
Así, Sherwell reproduce, al abordar el estudio del periodo de la independencia, el esquema historiográfico planteado al triunfo del grupo liberal en el que autores como Guillermo Prieto señalaron que la guerra de independencia, si bien fue en algunos casos violenta, se justificaba, pues pretendía cambiar un estado de cosas injusto impuesto por la dominación española. Ello dio como resultado que la época colonial fuera tachada como un periodo nefasto en la historia del país, surgiendo al respecto una "leyenda negra" sobre esa etapa (Galván, 2010: 104-105).

Consecuente con esa visión, Sherwell retrata a Miguel Hidalgo con las mejores virtudes e introduce a la narración de su vida con las preguntas que inducen a su admiración: ¿Quién no ha oído en nuestras grandes fiestas del 16 de septiembre decir con veneración y amor el nombre glorioso de don Miguel Hidalgo y Costilla? ¿Quién no ha tenido estremecida el alma al oírle llamar el "Padre de la Patria"? Como en otros libros escolares del porfiriato, prevalece en la narración del profesor veracruzano una asociación entre los héroes y el derrotismo. Si bien, como apunta Lucía Martínez Moctezuma, las narraciones sobre los héroes los presentan como modelo de virtudes y sacrificio por la patria, sus vidas acaban siempre en el martirio y la muerte, lo que conllevará también a provocar un sentimiento de gratitud con el personaje estudiado (Martínez, 2013: 17).

Otro de los aspectos que destacan en las lecturas es la exaltación de las virtudes de los héroes y los defectos de los personajes que alimentan la trama de las lecciones abordadas como una manera de insistir en los valores que deben de seguir los educandos. Así, Ignacio Allende, capitán de dragones, es "militar hábil y experimentado" y dispuesto al sacrificio de "todo" por la realización de sus ideales; Pípila es un "muchacho de 18 años de edad" que no tenía miedo; el Intendente Riaño, aunque fue enemigo de las tropas de los "mexicanos" "debe ser respetado por nosotros porque fue valiente y cumplió su deber como militar"; Morelos es presentado como "el más hábil y entendido", "el más glorioso quizá de nuestros guerreros", "valeroso insurgente", "la gloria más brillante de la guerra de Independencia, el terror de los realistas, la esperanza de la patria". En contrapartida, Félix María Calleja era "sanguinario y feroz como un tigre" y su nombre al parecer está "escrito con sangre en nuestra historia", mientras que Fernando VII es catalogado como "tirano, vicioso, cruel, retrógrado y malvado" (Sherwell, 1957: 42).

Al final de las temáticas, el autor dedica una lección a repetir los contenidos y propone ejercicios para la memorización de los niños por medio de preguntas y cuadros de series de sucesos como el cuadro: IV.- Serie de sucesos-Guerrero e Iturbide (página 44).

También recurre, en mayor o menor medida, al uso de los siete métodos que Rébsamen señalaba como parte de la enseñanza de la historia: el "método biográfico", insertando pequeñas síntesis de biografías de los personajes que aborda; el "método pragmático o filosófico", consistente en hacer preguntas sobre las causas de los fenómenos históricos y 


\section{IV.- Serie de sucesos-Guerrero e Iturbide}

\begin{tabular}{cl}
\hline Febrero de 1821 & Entrevista de Acatempan \\
24 de febrero de 1821 & Plan de Iguala \\
Agosto de 1821 & Toma de Puebla \\
Agosto de 1821 & Iturbide y O' Donojú firman los tratados de Córdoba \\
\hline
\end{tabular}

encontrar la lógica de la historia en toda su extensión, por ejemplo con la pregunta: "¿Qué causa importante produjo la guerra de Independencia?"; el método "cronológico" que presenta los hechos por "riguroso orden de sucesión", como la tabla arriba referida; y el método "sincrónico", que estudia simultáneamente los sucesos principales que en una época se verificaron en distintos lugares. Un ejemplo de esto último se aprecia en el ya citado capítulo de la guerra de la Independencia:

Cuando Morelos empezaba sus campañas, Hidalgo estaba en Guadalajara y abolía la esclavitud. Trece días después de que Morelos derrotó a Juan José París en Tres Palos, Hidalgo fue derrotado por Calleja en el Puente de Calderón (Sherwell, 1957: 59).

Entre tanto, el método "regresivo" pretendía ir de lo conocido a lo desconocido, el de "agrupación" reuniría lo semejante y el "comparativo", como su nombre lo indica, establecería semejanzas entre hechos o personajes de la misma naturaleza. Todos estos métodos deberían usarse, de acuerdo con el fundador de la normal de Xalapa, como una mezcla a fin de desarrollar las facultades de los niños (Rébsamen, 1904: 15-19).

\section{Conclusión}

Los libros de texto son objetos privilegiados de observación. Su estudio nos permite conocer cómo una sociedad concibió el conocimiento y lo trasmitió a la infancia por medio de las instituciones educativas, su recepción y evolución en el tiempo son elementos valiosos para entender el devenir educativo y su trascendencia en el tiempo.

Como parte consustancial de la cultura escolar, el libro de texto viene a ser un dispositivo más en la estandarización de la socialización escolar de los individuos que reciben educación y que se convertirán en receptores y trasmisores de los saberes aprendidos. De esta manera, este tipo de obras trascienden el ámbito educativo y se convierten en voceros 
de determinados grupos sociales en el poder, quienes a través de ellas tratan de imponer sus valores, identidades y formas de ver la realidad.

Guillermo Sherwell recibió una formación acorde con su época por lo que, desde los inicios de su desempeño profesional, trató de difundir una forma de entender la educación y la historia nacional. Este educador veracruzano formó parte de una red de "intelectuales educativos" bajo el liderazgo de Enrique C. Rébsamen quien, como su mentor y protector, le facilitó la entrada a este discípulo distinguido a un entramado de relaciones en el ámbito educativo, entramado formado por el grupo de alumnos del educador suizo que incursionaron en diversos niveles de la administración pública.

La formación recibida en la Escuela Normal de Xalapa permitió a Sherwell asumir y reproducir una serie de valores y experiencias que conformaron su visión sobre la formación docente, su papel en los procesos de enseñanza-aprendizaje, así como el funcionamiento del sistema educativo nacional, entonces en construcción.

Como "productor de saberes" Sherwell retomó el legado rebsamiano para la enseñanza de la historia. En su libro Historia Patria aplicó en su mayor parte la metodología que Rébsamen había señalado para ese conocimiento, la cual tenía como objetivo situar el estudio de la historia en los fines formales e ideales de la enseñanza y el desarrollo de las facultades intelectuales del niño, con ayuda de una serie de métodos que facilitaran dicha evolución.

\section{Fuentes}

Archivos

AENV Archivo de la Escuela Normal Veracruzana Enrique C. Rébsamen.

Bibliografía

Arteaga Castillo, Belinda y Siddharta Camargo Arteaga (2014), "Formar profesores y normalizar la enseñanza: el destino de las escuelas normales a finales del siglo XIx y la fundación de la Normal Veracruzana" en Luz Elena Galván Lafarga y Gerardo Antonio Galindo Peláez (coords.), Historia de la Educación en Veracruz, Gobierno del Estado de Veracruz, Universidad Veracruzana, México, pp. 269-290.

Bastián, Jean-Pierre (1993), Los disidentes, sociedades protestantes y revolución en México, 1872-1911, El Colegio de México, Fondo de Cultura Económica, México.

Blázquez D., Carmen y Ricardo Corzo Ramírez (1997), Colección de Leyes y Decretos de Veracruz, 18241919, T. I, Universidad Veracruzana, Xalapa.

Choppin, Alain (2000), "Los manuales escolares de ayer a hoy: el ejemplo de Francia", Historia de la Educación, Revista interuniversitaria, Universidad de Salamanca, Num. 19, pp. 13-37.

- (2000), "Pasado y presente de los manuales escolares" en Julio Ruíz Berrio (coord.), La cultura escolar de Europa, Biblioteca Nueva, Madrid, pp. 107-166. 
Connolly, Priscilla (1997), El contratista de don Porfirio, obras públicas, deuda y desarrollo desigual, Fondo de Cultura Económica-El Colegio de Michoacán-Universidad Autónoma Metropolitana Azcapotzalco, México.

Dossé, François (2007), El arte de la biografía, Universidad Iberoamericana, México.

Ducoing Watty, Patricia (2012), Quehaceres y saberes educativos del porfiriato, Colección Historia de la Educación, Universidad Nacional Autónoma de México-Instituto de Investigaciones sobre la Universidad y la Educación, México.

Galván Lafarga, Luz Elena (2010), "Memorias en papel. La historia como disciplina en el currículo de la escuela primaria, 1867-1940”, en Luz Elena Galván Lafarga y Lucía Martínez Moctezuma (coords.), Las disciplinas escolares y sus libros, Col. Ediciones Mínimas, Centro de Investigaciones y Estudios Superiores en Antropología Social-Universidad Autónoma del Estado de Morelos-Juan Pablos Editor, México, pp. 111-140.

Galván Lafarga, Luz Elena, Lucía Martínez Moctezuma y Oresta López Pérez (coords.), (2016) Más allá del texto, autores, redes de saber y formación de lectores, Centro de Investigaciones y Estudios Superiores en Antropología Social, Universidad Autónoma del Estado de Morelos, El Colegio de San Luis, México.

García Morales, Soledad (2003), Profesoras normalistas del porfiriato en Veracruz (1889-1911), Serie Jornada Magisterial, Secretaría de Educación y Cultura, Gobierno del Estado de Veracruz, Xalapa.

González Navarro, Moisés (1985), El porfiriato: vida social, Historia moderna de México, Editorial HERMES, México.

Guadarrama Olivera, Horacio (2013), "Córdoba: de la república restaurada a la revolución (1867-1910)" en Adriana Naveda Chávez-Hita y Enrique Florescano (coords.), Historia general de Córdoba y su región, Col. Veracruz Siglo XXI, Gobierno del Estado de Veracruz, Universidad Veracruzana, H. Ayuntamiento de Córdoba, México, pp. 177-310.

Hale, Charles A. (1991), La transformación del liberalismo en México a fines del siglo XIX, Col. La Reflexión, Vuelta, México.

Martínez Moctezuma, Lucía (2013), "Un país, una patria: Lecturas de historia en el Estado de México durante el porfiriato" en Alicia Civera Cerecedo (coord.), Experiencias educativas en el Estado de México. Un recorrido histórico, Fondo Editorial Estado de México-El Colegio Mexiquense A.C., México, pp. 151-180.

- (2014), "Una innovación pedagógica desde Veracruz. El dictamen del texto escolar para los pequeños lectores mexicanos" en Luz Elena Galván Lafarga y Gerardo Antonio Galindo Peláez (coords.), Gobierno del Estado de Veracruz, México, pp. 291-316

Moreno, Leticia (2005), "Una historia del pensamiento pedagógico en México", Tesis de Maestría en Ciencias de la Educación, ISCEEM, Toluca.

- (2016) "De Kreuzlingen a Jalapa: Enrique Conrado Rébsamen Egloff (1857-1904)" en Luz Elena Galván Lafarga y otros (coords.) Más allá del texto: autores, redes del saber y formación de lectores, Publicaciones de la Casa Chata-CIESAS-Universidad Autónoma del Estado de Morelos-El Colegio de San Luis, México, p. 287-314.

Olivo Lara, Margarita (1998), Biografías de veracruzanos distinguidos, Consejo Nacional para la Cultura y las Artes-Cobierno del Estado de Veracruz, tomos I y II, Col. Frondas Nuevas, Xalapa.

Pasquel, Leonardo (1983), Educadores veracruzanos, Col. Suma Veracruzana, Serie Biografía, Editorial Citlaltepetl, México.

Sherwell, Guillermo (1957), Historia Patria, segundo curso, Editorial Patria, S.A., México.

Vázquez, Josefina Zoraida (2000), Nacionalismo y educación en México, El Colegio de México, México.

Zea, Leopoldo (1968), El positivismo en México, Fondo de Cultura Económica, México. 
Zilli, Juan (1961), Historia de la Escuela Normal Veracruzana, Colección Suma Veracruzana, Editorial Citlaltépetl, México.

- (1966), Reseña Histórica de la Educación en el Estado de Veracruz, Editora del Gobierno del Estado de Veracruz, Jalapa.

Recursos electrónicos

Fuentes Bazán, María Eugenia (1999), "Los estudiantes del Instituto Metodista Mexicano y la Revolución Mexicana", Dimensión Antropológica, vol. 17, 31 de diciembre de 1999, pdf disponible en http://www. dimensionantropologica.inah.gob.mx/?p=1183 (fecha de consulta: 21/03/2016).

González Gómez, Carmen Imelda y Basaldúa Hernández, Manuel, "La formación de redes sociales en el estudio de actores y familias. Perspectiva de estudio en historia y antropología" en Redes. Revista hispana para el análisis de redes sociales, [S.I.], v. 12, n. 1, ene. 2007. ISSN 1579-0185. Disponible en: <https://revistes.uab.cat/redes/article/view/v12-nl-gonzalez-basaldua/104> ; doi:https://doi. org/10.5565/rev/redes.104 (fecha de consulta: 3/06/2019)

Heiland, Helmut (1999), "Friedridh Fröebel (1772-1852)", Oficina Internacional de Educación en www. ibe.unesco.org/sites/default/files/frobels.pdf (fecha de consulta: 18/12/2018).

Martínez García, Carlos (2013), "Nace en México la estrella de Belén", Protestante Digital.com MACACín, Kairos y Kronos 17 de agosto de 2013 (fecha de consulta: 05/08/2016).

Moreno, Leticia (2011), Los maestros intelectuales educativos 1889-1910, XI Congreso Nacional de Investigación Educativa/9. Historia e Historiografía de la Educación/Ponencia, en www.comie.org.mx/ congreso/memoriaelectronica/vll/docs/area_09/0414.pdf (fecha de consulta: 13/05/2018).

Rébsamen, Enrique C. (1904), Guía metodológica para la enseñanza de la historia en las escuelas primarias elementales y superiores de la República Mexicana, disponible en: http://cdigital.dgb.uanl.mx/ la/1080022604/1080022604.html (fecha de consulta: 15/08/2016).

Mendiola, Alfonso y Guillermo Zermeño (1994), La función social de los libros de Historia en la España imperial de los siglos XVI y XVII, disponible en: https://www.estudioshistóricos.inah.gob.mx/revistaHistorias/wpcontent/uploads/historias_31_49-56.pdf.

Ortega y Medina, Juan (2001), Polémicas y ensayos mexicanos en torno a la Historia, Universidad Nacional Autónoma de México, Formato PDF, publicado en línea: 7 de marzo de 2017, disponible en: http://www.historicas.unam.mx/publicaciones/publicadigital/libros/polemicas/ensayos_mexicanos. html (fecha de consulta: 20/11/2018).

Trujillo Bolio, Mario (1997), Operarios fabriles en el Valle de México (1864-1884), CIESAS-El Colegio de México, México. http://www.históricas.unam.mx/publicaciones/publicadigital/libros/polemicas/ ensayos_mexicanso.html (fecha de consulta: 17/02/2019).

Gerardo Antonio Galindo Peláez realizó estudios de licenciatura en Historia en la Facultad de Historia de la Universidad Veracruzana, donde se ha desempeñado como profesor y en la que ha fungido como director. Es maestro y doctor en Historia por la Universidad Iberoamericana, plantel Santa Fe en la Ciudad de México. Es miembro del Cuerpo Académico "Estudios Históricos de la Región del Golfo en los Siglos XIX y XX". Ha publicado diversos artículos y trabajos de investigación entre los que destaca: "Formar en los corazones el culto por lo bueno y lo bello. Acercamientos a María Enriqueta Camarillo y Rosas de la Infancia. Educar para la sociedad y el Estado" (inédito). Es autor del libro El Colegio Preparatorio de Orizaba 1824-1910: continuidad y cambio (Universidad Veracruzana, 2013) y 
coordinador, junto con Luz Elena Galván, del volumen Historia de la Educación en Veracruz (Universidad Veracruzana, Secretaría de Educación de Veracruz, 2014).

Recibido: 12 de marzo de 2019

Aceptado: 3 de junio de 2019 